\title{
Phototherapy for neonatal hyperbilirubinaemia: the importance of dose
}

\author{
N MODI AND A J KEAY \\ Medical Paediatric Unit, Western General Hospital, Edinburgh
}

SUMmARY The management of neonatal jaundice can be made much easier using simple methods that increase the radiant energy in the range 420 to $480 \mathrm{~nm}$. Two groups of infants being treated for physiological jaundice during a period of 6 months were compared. The first group received treatment from two unmodified phototherapy units and the second from two units in which the horizontal frames housing the tube lights were lowered, thus providing a higher 'dose' of phototherapy. Measurements of irradiance from the four units were compared. An improvement in treatment was noted in the group receiving the higher dose with a decrease in duration of treatment and a greater rate of fall in the level of serum bilirubin. A dose response relationship was thus confirmed. Comparisons between previous studies are hindered by failure to recognise the varying contribution of background irradiance, the use of radiometers with differing spectral responses, and the use of different units for expressing results. Failure to appreciate the importance of dose must largely be responsible for the present wide variability in the effectiveness of phototherapy.

Although there was intital scepticism, phototherapy is now accepted as a safe treatment in the management of neonatal unconjugated hyperbilirubinaemia. Cremer et al., ${ }^{12}$ reporting first in 1958, made two important observations: (1) that the spectral range $420-480 \mathrm{~nm}$-that is blue light-is therapeutically effective; (2) that daylight appears to be more efficient in reducing serum bilirubin levels than specially constructed sources of blue light. No explanation was offered for this. Neither did they mention the actual quantity of radiant energy received by the infant; in other words they failed to realise the importance of this initial observation as a probable effect of dose, considerably higher outside on a sunny day than under standard phototherapy units. What early measurements were made concentrated on total illuminance rather than irradiance within the specific $420-480 \mathrm{~nm}$ range. No real advances in the clinical application of phototherapy were made until Sisson et al. $^{3}$ in 1972 , and most recently $\operatorname{Tan}^{4}$ in 1977 and 1982 reported a dose response relationship. Despite these findings commercial phototherapy units still provide irradiances which vary widely. It is by no means standard practice in newborn nurseries to measure the actual dose of radiant energy received by the infant. This study shows that careful measurement of dosage enables the optimal and effective use of phototherapy units.

\section{Methods}

Four commercial phototherapy units were used for this study: two Narco Air Shields S 400s (units 2 and 4), and two Vickers Medical units (units 1 and 3). Under standard nursery lighting conditions (neon striplights continuously on) measurements of irradiance were made at $50 \mathrm{~cm}$, the conventional position of the infant. The height of the frames housing the tube lights was then lowered as far as possible in units 1 and 4 -that is one from each pair, and repeat measurements made at infant level.

Measurements of irradiance were made using a Macam R450 (Macam Photometrics, Livingston. Present cost: £300). This is a small, portable, battery-run radiometer, the optical detector of which is a solid state photodiode with optical filters $\vec{N}$ to give a spectral response with cosine corrected angular response to match the bilirubin phototherapy action spectrum, between 430 and $475 \mathrm{~nm}$. The sensor has a peak sensitivity at $450 \mathrm{~nm}$ and half 0 maximum sensitivities at 429 and $475 \mathrm{~nm}$. The range of measurements is from 0 to $1.2 \mathrm{~mW} / \mathrm{cm}^{2}$. Calibration was checked using a standard, itself calibrated to the specifications of the US National Bureau of Standards.

All infants requiring treatment of simple, physiological jaundice during a period of 6 months were entered into the trial. There were 21 boys and 16 
girls. Preterm infants, sick infants, infants with evidence of haemolysis, and those developing jaundice requiring treatment in the first 48 hours of life were thus excluded. All infants had a full blood count, blood film, blood group, and direct Coombs's test. Some had additional investigations.

Measurements of serum bilirubin were made using a standard spectrophotometric method for total bilirubin ${ }^{6}$ with a within-batch precision of $2.2 \%$ at $220 \mu \mathrm{mol} / \mathrm{l}$ and $2.9 \%$ at $165 \mu \mathrm{mol} / 1$, and a between-batch coefficient of variation of $7.6 \%$ at a mean of $203 \mu \mathrm{mol} / \mathrm{l}$.

Treatment was started at levels of bilirubin at or exceeding $200 \mu \mathrm{mol} / 1$ and stopped when they fell below $200 \mu \mathrm{mol} / \mathrm{l}$. Treatment was continuous except for interruptions during feeding and changing. Measurements of serum bilirubin were made at 12 hourly intervals, at 9 am and $9 \mathrm{pm}$, and if possible, at 12 and 24 hours after stopping treatment. Discharge from hospital was not delayed for the purposes of the study. The phototherapy units, numbered 1 to 4 , were used in strict numerical order.

Note was made of the total duration of treatment in hours. Measurements of irradiance at infant level were made at least once during each treatment to ensure continuing adequate outputs from each phototherapy unit.

\section{Results}

Measurements of irradiance at infant level in each of

Table 1 Irradiance at infant level

\begin{tabular}{|c|c|c|c|c|c|c|}
\hline \multicolumn{7}{|c|}{ Phototherapy unit } \\
\hline \multicolumn{4}{|l|}{ Vickers } & \multicolumn{3}{|c|}{ Narco Air Shields } \\
\hline & Unit 1 & Unit 1 & Unit 3 & Unit 2 & Unit 4 & Unit 4 \\
\hline $\begin{array}{l}\text { Height (cm) } \\
\text { Irradiance } \\
\left(\mathrm{mW} / \mathrm{cm}^{2}\right)\end{array}$ & $\begin{array}{l}50 \\
0.48\end{array}$ & $\begin{array}{l}36 \\
1.08\end{array}$ & $\begin{array}{l}50 \\
0.4\end{array}$ & $\begin{array}{l}50 \\
0.4\end{array}$ & $\begin{array}{l}50 \\
0.4\end{array}$ & $\begin{array}{l}44 \\
0 \cdot 68\end{array}$ \\
\hline
\end{tabular}

units 1, 2, 3, and 4 and after lowering in units 1 and 4 are shown (Table 1). Further comparative results are shown (Table 2) for each group of infants under individual units, and for the combined groups under units 1 and 4 and units 2 and 3 .

The mean levels of bilirubin at which treatment was begun show good comparability with, if anything, higher starting levels in the adjusted units 1 and 4.

The duration of therapy for the two groups is compared. Treatment time is defined as the total time elapsed from the first reading above $200 \mu \mathrm{mol} / \mathrm{l}$ to the first reading below $200 \mu \mathrm{mol} / 1$. Using Wilcoxons's rank sum test a highly significant reduction in treatment time is found in the group of infants under phototherapy units 1 and 4 , the lowered units $(P<0.01)$. Only two infants, one in group 1 and one in group 4, required a second treatment period. There were too few to determine whether this represents a significant rebound phenomenon.

We have also compared the fall in the level of serum bilirubin/hour while under treatment. The test statistic has been applied to the calculation of fall in serum bilirubin/hour as follows:

(first bilirubin measurement while under phototherapy)-(first bilirubin measurement below 200 umol/l while under phototherapy)/(time between the two measurements).

A highly significant difference in fall in serum bilirubin/hour is found $(P<0.0001)$ with an increased fall in the group of infants under units 1 and 4 which provided the higher irradiance at infant level.

The age of the infants, all term, at the start of treatment ranged from 3 to 5 days. We know that the fall in serum bilirubin is not necessarily linear during this period and that there are physiological fluctuations in bilirubin while under treatment. Nevertheless, as treatment times varied widely, this would appear to provide the most appropriate comparison.

Table 2 Comparative data of 4 individual and 2 combined groups of infants

\begin{tabular}{|c|c|c|c|c|c|c|}
\hline \multirow{2}{*}{. } & \multicolumn{6}{|c|}{ Phototherapy unit } \\
\hline & $\begin{array}{l}\text { Unit 1 } \\
\text { (lowered) }\end{array}$ & Unit 2 & Unit 3 & $\begin{array}{l}\text { Unit } 4 \\
\text { (lowered) }\end{array}$ & $\begin{array}{l}\text { Units } 1+4 \\
\text { (lowered pair) }\end{array}$ & Units $2+3$ \\
\hline $\begin{array}{l}\text { Irradiance } \mathrm{mW} / \mathrm{cm}^{2} \\
\text { Mean age at start of therapy (hours) } \\
\text { Mean birthweight }(\mathrm{kg}) \\
\text { Number of infants } \\
\text { Bilirubin }(\mu \mathrm{mol} / \mathrm{l}) \text { at start of therapy } \\
\text { Mean (SD) } \\
\text { Duration of therapy (hours) } \\
\text { Mean (SD) } \\
\text { Decline in bilirubin/hour ( } \mu \mathrm{mol} / \mathrm{l}) \\
\text { Mean (SD) }\end{array}$ & $\begin{array}{l}1 \cdot 08 \\
78 \cdot 4 \\
3 \cdot 23 \\
13 \\
241 \cdot 3 \\
(36 \cdot 4) \\
42 \cdot 4 \\
(20 \cdot 7) \\
1 \cdot 94 \\
(0 \cdot 57)\end{array}$ & $\begin{array}{l}0 \cdot 4 \\
81 \cdot 7 \\
3 \cdot 39 \\
10 \\
228 \cdot 7 \\
(28 \cdot 1) \\
50 \cdot 6 \\
(16 \cdot 5) \\
1 \cdot 21 \\
(0 \cdot 95)\end{array}$ & $\begin{array}{l}0 \cdot 4 \\
80 \cdot 0 \\
3 \cdot 0 \\
6 \\
235 \cdot 8 \\
(20 \cdot 9) \\
42 \cdot 7 \\
(10 \cdot 5) \\
1 \cdot 42 \\
(0 \cdot 43)\end{array}$ & $\begin{array}{l}0 \cdot 68 \\
90 \cdot 1 \\
3 \cdot 41 \\
8 \\
230 \cdot 1 \\
(23 \cdot 2) \\
33 \cdot 9 \\
(15 \cdot 4) \\
2 \cdot 99 \\
(3 \cdot 85)\end{array}$ & $\begin{array}{l}84 \cdot 3 \\
3 \cdot 32 \\
21 \\
236 \cdot 7 \\
(32 \cdot 1) \\
38 \cdot 0 \\
(21 \cdot 4) \\
2 \cdot 31 \\
(2 \cdot 4)\end{array}$ & $\begin{array}{l}80 \cdot 9 \\
3 \cdot 20 \\
16 \\
231 \cdot 4 \\
(25 \cdot 8) \\
47 \cdot 6 \\
(15 \cdot 1) \\
1 \cdot 29 \\
(0 \cdot 8)\end{array}$ \\
\hline
\end{tabular}




\section{Discussion}

The management of jaundice in the newborn is notoriously imprecise. Though a self limiting problem in the majority of instances it may lead to a spectrum of complications of increasing severity. It is impossible to be certain at what level unconjugated hyperbilirubinaemia becomes significant and requires treatment. This treatment level is of course variable and depends on the gestational age, chronological age, and clinical condition of the infant as much as on the actual level of serum bilirubin. The criteria for instituting and stopping treatment thus vary widely between units. Added to such clinical uncertainties are the inherent errors in laboratory measurement, the rapid physiological changes in bilirubin levels, and in particular the varying additional therapeutic effect of daylight. That daylight sources of blue light are significant, even in a city such as Edinburgh, which is not renowned for its sunshine, has been well demonstrated in previous work from this department (Smith et al., unpublished data). Such an effect is obviously very variable; particularly if cities in the northern hemisphere are compared with those in the tropics.

A dose response relationship in the use of phototherapy has been demonstrated by Mims et al. ${ }^{7}$ and Bonta and Warshaw ${ }^{8}$ using conventional phototherapy units, and by $\operatorname{Tan}^{4}{ }^{5}$ and Sisson et al. ${ }^{3}$ using specially constructed frames. As radiance varies inversely with the square of the distance it is obvious that decreasing the distance between baby and light source provides a higher dose of radiant energy. We have shown that such simple modifications, leading to an increase in radiant energy received at infant level from $0.48 \mathrm{~mW} / \mathrm{cm}^{2}$ to $1.08 \mathrm{~mW} / \mathrm{cm}^{2}$ and from $0.4 \mathrm{~mW} / \mathrm{cm}^{2}$ to $0.68 \mathrm{~mW} / \mathrm{cm}^{2}$, has resulted in an appreciable improvement in our management of neonatal jaundice with a decrease in treatment time and an increase in the rate of fall of bilirubin levels. No adverse effect was noted in the infants receiving the higher dosage. Furthermore, as the overall illuminance within the treatment cubicle remained the same, with no introduction of blue light sources, nursing and clinical evaluation of the babies undergoing treatment was not impaired, nor were the staff troubled with the headaches and dizzyness often experienced when exposed to high intensity blue light.

We feel that there is a need to appreciate that commercial phototherapy units vary widely in their outputs in the 420-480 range and that these outputs are generally suboptimal. Optimal therapeutic irradiance, however, has yet to be adequately defined. Bonta and Warshaw ${ }^{8}$ suggest a minimal effective irradiance of $4.0 \mu \mathrm{W} / \mathrm{cm}^{2}$ per $\mathrm{nm}$ measuring with an IL 155 Color Radiometer (International Light Inc. USA). This has a filter which allows a wider wavelength band (half maximum sensitivities at 385 and $507 \mathrm{~nm}$ ) than the radiometer used in this study and that used by $\operatorname{Tan}^{4}$ (UDT: United Detector Technology, USA. Half maximum sensitivities at 425 and $500 \mathrm{~nm}$ ). Although irradiance in the phototherapeutic range may thus have been correspondingly less, the study by Hammerman et al..$^{9}$ suggests that Bonta's measurement would approximate to $274 \mu \mathrm{W} / \mathrm{cm}^{2}$ on the UDT radiometer. This is in remarkable contrast to the minimal effective radiance of $15.25 \mu \mathrm{W} / \mathrm{cm}^{2}$, in the $425-475 \mathrm{~nm}$ range, suggested initially by Tan, ${ }^{4}$ also using a UDT radiometer and to his later figure of 50.26 $\mu \mathrm{W} / \mathrm{cm}^{2}{ }^{4} 5$

Tan further suggests a saturation effect occurring in the region of $0.58 \mathrm{~mW} / \mathrm{cm}^{2}$ and subsequently at $1.6 \mathrm{~mW} / \mathrm{cm} .^{215}$ Irradiance provided by our two groups of high and low dosage lie on either side of $0.58 \mathrm{~mW} / \mathrm{cm}^{2}$ and a significant difference in the rate of fall of serum bilirubin levels has been shown. Sisson et al., ${ }^{3}$ measuring in the 420-490 range, have demonstrated a highly significant difference in the 24-hour fall of bilirubin in two groups of infants receiving 0.9 and $2.9 \mathrm{~mW} / \mathrm{cm}^{2}$. We also note that 24-hour declines in bilirubin in our high dose group $\left(0.68-1.08 \mathrm{~mW} / \mathrm{cm}^{2}\right.$, range $\left.430-475 \mathrm{~nm}\right)$ are of the order of $55.2 \mu \mathrm{mol} / 1$. This approximates to the 24-hour declines of $59.5 \mu \mathrm{mol} / 1$ achieved by Sisson et $\mathrm{al}^{3}{ }^{3}$ in their high dose group $\left(2.9 \mathrm{~mW} / \mathrm{cm}^{2}\right.$, range $420-490 \mathrm{~nm}$ ) and of the $59.5 \mu \mathrm{mol} / 1$ also achieved by Mims et al. ${ }^{7}$ in their group receiving $8.63 \mu \mathrm{W} / \mathrm{cm}^{2} /$ $\mathrm{nm}$. Using the data of Hammerman et al. ${ }^{9}$ this corresponds to $0.8 \mathrm{~mW} / \mathrm{cm}^{2}$ in the $420-470 \mathrm{~nm}$ range. Each of these 24-hour declines is considerably lower than that achieved by Tan's group of infants receiving $0.85 \mathrm{~mW} / \mathrm{cm}^{2}$ (range $425-475 \mathrm{~nm}$ ), namely $113.9 \mu \mathrm{mol} / 1^{4}$. This suggests the possibility of an additional effect of background daylight and implies that nurseries in the northern hemisphere require phototherapy units with a correspondingly higher radiant energy output in the therapeutic range. It would appear that a saturation point, if such exists, probably occurs between 1 and 3 $\mathrm{mW} / \mathrm{cm}^{2}$ and that at present nurseries should aim to provide a minimum irradiance of $1 \mathrm{~mW} / \mathrm{cm}^{2}$ in the $420-480 \mathrm{~nm}$ range.

We should stress that variations in irradiance readings for the same phototherapy unit with different radiometers are often due to variations in peak absorption and absorption band widths of the individual spectral filters. We feel that measurements will vary significantly with time of day and position of the infant due to the effect of daylight. Comparable measurements of radiant energy outputs from 
phototherapy units require baseline readings in a dark room without ambient lighting. Radiometers used should incorporate a filter with a spectral response designed to match the bilirubin phototherapy action spectrum. It should be noted that measurements of irradiance may be made in $\mu \mathrm{W} / \mathrm{cm}^{2}$, $\mathrm{mW} / \mathrm{cm}^{2}, \mu \mathrm{W} / \mathrm{cm}^{2}$ per $\mathrm{nm}$, or $\mathrm{mW} / \mathrm{cm}^{2}$ per $\mathrm{nm}$. As this gives a measure of total radiant energy over the appropriate wavelength range we prefer to use $\mu \mathrm{W}$ or $\mathrm{mW} / \mathrm{cm}^{2}$. Precise information regarding the total dose of irradiation received by an infant under phototherapy requires continuous 24-hour monitoring which is not practical for everyday use in newborn nurseries. It is evident, however, that possession of a radiometer will enable one to determine whether positioning an infant near a window on a sunny day will provide a better therapeutic irradiance than positioning under a suboptimal phototherapy unit.

Failure to appreciate the importance of dose must largely be responsible for the present wide variability in the effectiveness of phototherapy. We regard phototherapy without measurement of irradiance as incomplete and inefficient.

We thank Dr J Syme for permission to study patients under his care; Dr D H Wright for assistance with radiometer calibration; Dr D A Horne and the Department of Biochemistry, Western General Hospital, for carrying out the measurements of serum bilirubin; Dr Freda Alexander and Mr A Birtwhistle of the Department of Medical Statistics, University of Edinburgh, for statistical assistance; the resident medical and nursing staff for their diligence in the collection of data.

\section{References}

1 Cremer R J, Perryman P W, Richards D H. Influence of light on hyperbilirubinaemia of infants. Lancet 1958; 1 : 1094-7.

2 Dobbs R H, Cremer R J. Phototherapy. Arch Dis Child 1975; 50: 833-6.

${ }^{3}$ Sisson T R C, Kendall N, Shaw E, Kechavarz-Oliai L. Phototherapy of jaundice in the newborn infant. IJ. Effect of various light intensities. J Pediatr 1972; 81 : 35-8.

4 Tan K L. The nature of the dose response relationship of phototherapy for neonatal hyperbilirubinaemia. J Pediatr 1977; 90: 448-52.

5 Tan K L. The pattern of bilirubin response to phototherapy for neonatal hyperbilirubinaemia. Pediatr Res 1982 ; 16: 670-4.

6 White D, Haidar G A, Reinhold J G. Spectrophotometric measurement of bilirubin concentrations in the serum of the newborn by the use of a microcapillary method. Clin Chem 1958; 4: 211-22.

7 Mims L C, Estrada M, Gooden D S, Caldwell R R, Kotas R V. Phototherapy for neonatal hyperbilirubinaemia-a dose response relationship. Fetal and Neonatal Medicine 1973; 83: 658-62.

8 Bonta B W, Warshaw J B. Importance of radiant flux in the treatment of hyperbilirubinemia: failure of overhead phototherapy units in intensive care units. Pediatrics 1976; 57: 502-5.

- Hammerman C, Eidelman A I, Lee K S, Gartner L M. Comparative measurements of phototherapy: a practical guide. Pediatrics 1981; 67: 368-72.

Correspondence to Dr Neena Modi, Lecturer in Paediatrics, Neonatal Unit, University College Hospital, Gower Street, London WC1E 6AE.

Received 28 January 1983. 